\title{
Relationship of electrodermal lability and reflex sensitivity to differential conditioning '
}

\author{
ANDREW CRIDER AND BERNARD TURSKY \\ HARVARD MEDICAL SCHOOL AND MASSACHUSETTS MENTAL HEALTH CENTER
}

\begin{abstract}
Differential electrodermal (skin potential) conditioning was established in a group of 38 Ss. Two measures of unconditioned electrodermal activity correlated highly with both $\mathrm{CS}+$ and CS- response magnitudes during a series of extinction test trials. No relationship was found, however, between the unconditioned activity measures and differential conditioning.
\end{abstract}

A number of authors have suggested that galvanic skin response (GSR) conditioning is related to various indices of unconditioned electrodermal activity (Martin, 1960, 1963; Purohit, 1966; Stern, Stewart, \& Winokur, 1961; Stern, Winokur, Stewart, \& Leonard, 1963; Winokur, Guze, Stewart, Pfeiffer, Stern, \& Hornung, 1959). In these studies, amount of conditioning has been shown to be substantially correlated with individual differences in both electrodermal lability (spontaneous responding under resting conditions) and reflex sensitivity (CS evoked responding prior to conditioning). All of the studies employed a simple defensive conditioning paradigm, however, in which response enhancement specific to CS-UCS pairing is confounded with a variety of nonspecific phenomena that influence response levels, as, for example, sensitization due to the introduction of a noxious UCS. As these nonspecific phenomena are likely to be correlated with lability and reflex sensitivity (Johnson, 1963), it is possible that the reported correlations reflect a general factor of electrodermal responsiveness rather than a relationship between unconditioned and conditioned activity. The present study reevaluates this issue in the context of differential conditioning, which allows for the assessment of responsiveness to a control stimulus not paired with the UCS.

Method

The present data derive from a study in which CS+ trials were terminated with a 1 sec shock UCS either by the occurrence of a criterion electrodermal response or, failing that, after a 15 sec CS-UCS interval. As a short latency response to CS+ onset was found to occur in the great majority of cases, the UCS was made contingent on any second response with a latency of $5 \mathrm{sec}$ or greater following CS+ onset. In all cases, CS- duration was $15 \mathrm{sec}$. An experimental group of 19 Ss was compared with 19 control Ss matched on resting lability, and yoked trial by trial with the experimental Ss. The control Ss thus received the UCS at equivalent temporal points following CS+ onset but randomly with respect to response occurrence. As will be reported elsewhere, no differences were found between these two groups on a series of extinction test trials, and the following correlations are based on a pooled $\mathrm{N}$ of 38 .

Conditional stimuli were generated by an audio frequency oscillator and delivered through a speaker placed above and behind the S. Two tones -400 and 900 $\mathrm{Hz}$, of $70 \mathrm{~dB}$ loudness measured at the position of the $S$-alternated between Ss as either CSt or CS-. The shock UCS was delivered to the right forearm via a system previously described (Tursky \& Watson, 1964). Its intensity was set a few tenths of a mA above each S's criterion of painfulness. The Ss were seated in a sound attenuated, temperature controlled room visible from the recording chamber via a one-way mirror.

Palmar electrodermal activity was recorded as the potential difference between two $\mathrm{Ag}-\mathrm{AgCl}$ sponge electrodes placed on the left palm and forearm. The signal was passed through an RC coupled amplifier having an input time constant of $3 \mathrm{sec}$ to distinguish the more rapid fluctuations of interest from slower DC shifts. A criterion response on CS+ trials was defined as any negative going fluctuation of $0.25 \mathrm{mV}$ or greater. This measure was in turn quantified on line by use of a cumulative integrator, whose polygraph readout was a ramp function that provided a running record of total accumulated voltage change over time (Tursky, 1964).

Resting electrodermal lability was measured as the number of $\mathrm{mm}$ of pen excursion of integrated activity during a $5 \mathrm{~min}$ preexperimental resting period. This was followed by a block of four trials presented in the order CS-, CSt, CSt, CS- in which both CSs were presented for $15 \mathrm{sec}$. Reflex sensitivity was taken as the sum of the integrated activity during CS presentation on the first two trials, allowing for a measure of responsiveness to both tones independent of any excitatory effects due to UCS introduction at the end of the second trial. This was followed by $12 \mathrm{CS}+$ and $12 \mathrm{CS}$ - trials during which the response-reinforcement contingency was in effect. These trials, as well as the eight extinction test trials that immediately followed, were presented in four trial blocks of either $+-+_{+}$ or -++ - order. During extinction, both CS+ and CStrials were of $15 \mathrm{sec}$ duration. Throughout the experiment, intertrial intervals varied from 45 to $75 \mathrm{sec}$ around a mean of $60 \mathrm{sec}$.

\section{Results and Discussion}

Conditioning was assessed by finding the total amount of integrated activity generated separately during the four CSt and four CS- extinction trials. The mean difference between these sums across 38 Ss repre- 
Table 1 Correlations of electrodermal lability and reflex sensitivity with conditioning measures*

\begin{tabular}{lcccc} 
& CSt & CS- & (CS+) + (CS-) & (CS+) - (CS-) \\
Lability & .52 & .64 & .59 & -.14 \\
Sensitivity & .68 & .61 & .70 & .13 \\
\hline
\end{tabular}

${ }^{*} p=.01$ for $r h o=.41$

sented the differential conditioning effect, which was significantly different from zero in the expected direction $(t=3.66, p<.001)$.

Rank order correlations were then computed between lability and sensitivity on the one hand and total CS+, total CS-, overall, and differential activity during extinction on the other (Table 1). Both indices of unconditioned activity are strongly related to $\mathrm{CS}+$ and CS- activity and to their sum. Scatter plots of these relationships showed them to be essentially linear. No correlation was found, however, between either lability or sensitivity and differential responding. The scatter plots of these two relationships showed no evidence of nonlinear trends. As would be anticipated, lability and sensitivity were substantially intercorrelated (rho $=0.58$ ).

These data agree with the previously cited findings relating unconditioned electrodermal activity to $\mathrm{CS}+$ responding. They also demonstrate, however, that similarly high correlations hold between these measures and both CS- and overall responding. When the contribution of nonspecific factors is controlled by taking the differential response as the criterion of conditioning, no relationship is apparent between unconditioned and conditioned activity. It is noteworthy that a similar lack of relationship is found between resting lability and asymptotic response rate when the electrodermal response is instrumentally conditioned (Crider, Shapiro, \& Tursky, 1966).

Electrodermal lability and reflex sensitivity are reliable characteristics of the individual (Lacey \& Lacey, 1962; Johnson, 1963). As such, they are dis- appointingly similar to other measures of individual differences such as Manifest Anxiety and IntroversionExtraversion in their inability to predict electrodermal conditioning levels with any degree of accuracy (Lovibond, 1964). The reason may be that true electrodermal conditioning is itself an unreliable criterion, more subject to transient situational factors than to stable individual differences. Little is known of the stability of electrodermal conditioning.

\section{References}

CRIDER, A., SHAPIRO, D., \& TURSKY, B. Reinforcement of spontaneous electrodermal activity. J. comp. physiol. Psychol., 1966, 61, 20-27.

JOHNSON, L. C. Some attributes of spontaneous electrodermal activity. J. comp. physiol Psychol, 1963, 56, 415-422.

LACEY, J. I., \& LACEY, B. C. The law of initial value in the longitudinal study of autonomic constitution: reproducibility of autonomic responses and response patterns over a four-year interval. $A n n . N . Y$. Acad. Sci, 1962, 98, 1257-1326.

LOVIBOND, S. H. Personality and conditioning. In B. A. Maher (Ed.) Progress in experimental personality research. Vol. 1. New York: Academic Press, 1964. Pp. 115-168.

MARTIN, I. Variations in skin resistance and their relationship to GSR conditioning. J. ment. Sci, 1960, 106, 281-287.

MARTIN, I. A further attempt at delayed GSR conditioning. Brit. $J$. Psychol, 1963, 54, 359-368.

PUROHIT, A. P. Personality variables, sex-difference, GSR responsiveness, and GSR conditioning. $J$. exp. res. Pers., 1966, 1, 166-173.

STERN, J. A., STEWART, M. A., \& WINOKUR, G. An investigation of some relationships between various measures of galvanic skin response. J. psychosom. Res, 1961, 5, 215-223.

STERN, J. A., WINOKUR, G., STEWART, M. A., \& LEONARD, B. A. Electrodermal conditioning: some further correlates. J. nerv. ment. Dis., 1963, 137, 479-486.

TURSKY, B. Integrators as measuring devices of bioelectric output. Clin. pharmacol. Therap., 1964, 5, 887-892.

TURSKY, B., \& WATSON, P. Controlled physical and subjective intensities of electric shock. Psychophysiology, 1964, 1, 151-162.

WINOKUR, G., GUZE, S., STEWART, M. A., PFEIFFER, E., STERN, J. A., \& HORNUNG, F. Association of conditionability with degree of reactivity in psychiatric patients. Science, 1959, 129, 1423-1424. Note

1. Supported by NIMH Grant MH-04172. 